\title{
Los derechos humanos como herramienta de disputa de comunidades indígenas y organizaciones campesinas frente al Estado paraguayo
}

Human rights as a tool for the dispute of indigenous communities and peasant organizations against the Paraguayan State

Os direitos bumanos como ferramenta de disputa das comunidades indigenas e organizações camponesas contra o Estado paraguaio.

Les droits de l'bomme en tant qu'outil pour le différend des communautés indigènes et des organisations paysannes contre l'État paraguayen 人权是解决土著社区和农民组织对巴拉圭国家的争端的工具

\section{Valerio Olguin ${ }^{1}$}

Universidad Autónoma San Luis Potosí - México

Revista Derechos en Acción ISSN 2525-1678/ e-ISSN 2525-1686

Año 5/No 16 Invierno 2020 (21 junio a 20 septiembre), 166-190

DOI: https://doi.org/10.24215/25251678e418

Recibido: 03/05/2020

Aprobado: 07/07/2020

Resumen: En general, este artículo describe un estudio que analizó la viabilidad del uso del derecho y los derechos humanos como herramienta de resistencia y transformación social de comunidades indígenas y

\footnotetext{
Lic. En Trabajo Social por la Universidad Nacional de Asunción. Estudiante de la Maestría en Derechos humanos en la Universidad Autónoma de San Luis Potosí. Dirección: México, San Luis Potosí, Capital. Av. Del Lago Ex.: 355 In.: 2302. Entre Av. Del Parque y BLV. Del Rio Santiago. (ORCID: https://orcid.org/0000-0003-2889-554X).
} 
organizaciones campesinas de Paraguay a través de un estudio de casos. Es un estudio con perspectiva cualitativa, que, mediante el análisis de los repertorios jurídicos utilizados por los movimientos sociales, campesinos e indígenas, también examinó los factores que inciden para que estas hagan uso del uso del derecho y los derechos humanos como herramienta de resistencia, lo que finalmente permitió identificar los principales obstáculos y límites para garantizar los derechos humanos de estas comunidades y organizaciones del país. Entre los principales resultados se señalan la posibilidad del cambio normativo y la reparación social asumidos como posibles oportunidades políticas que podrían impulsar y expandir los derechos de la población indígena-campesina en el país, siempre y cuando exista un ambiente político e institucional que lo favorezca, y, además se cuente con las estructuras de soportes suficientemente capaces de sostener este tipo de procesos.

Palabras clave: Movilización Socio-legal, movimientos sociales, Estructura de Oportunidades políticas y derechos humanos.

Abstract: This is an investigation that analyzes the viability of the use of law and human rights as a tool for resistance and social transformation of indigenous communities and peasant organizations in Paraguay through a case study. This, analyzes the use of legal and non-legal repertoires used in each of the cases that involve social mobilization. The study was carried out in the city of Asunción, Paraguay, started in August 2018 and ended in December 2019. The research areas include: legal sociology, social movements, collective action within the studies of the law, the MSL and human rights. It is a study with a qualitative perspective, where in addition to the viability of the use of law and human rights, the factors that influence the use of law and the defense of human rights of these subjects are examined to finally identify the main obstacles and limits to guarantee the human rights of these communities and organizations. Among the main results are the possibility of regulatory change and social reparation assumed as political opportunities that could promote and expand the rights of the indigenous-peasant population in the country, as long as there is a political and institutional environment that favors it, and In addition, the support structures are sufficiently capable of supporting this type of process.

Keywords: Socio-legal mobilization, social movements, Structure of political opportunities and human rights. 
Resumo: Em geral, este artigo descreve um estudo que analisou a viabilidade do uso do direito e dos direitos humanos como instrumento de resistência e transformação social de comunidades indígenas e organizações camponesas no Paraguai através de um estudo de casos. É um estudo com perspectiva qualitativa, que, através da análise dos repertórios jurídicos utilizados pelos movimentos sociais, camponeses e indígenas, também examinou os fatores que influenciam para que estas fazem uso do direito e dos direitos humanos como instrumento de resistência, o que finalmente permitiu identificar os principais obstáculos e limites para garantir os direitos humanos dessas comunidades e organizações no país. Entre os principais resultados são apontados a possibilidade de mudança normativa e reparação social assumidos como possíveis oportunidades políticas que poderiam promover e ampliar os direitos da população indígena e camponesa no país, sempre que exista um ambiente político e institucional favorável, e, além disso, que as estruturas de apoio sejam suficientemente capazes de sustentar esse tipo de processo.

Palavras-chave: Mobilização sócio-legal, movimentos sociais, estrutura de oportunidades políticas e direitos humanos.

Résumé: cet article décrit une étude qui a analysé la viabilité de I'utilisation du droit et des droits de l'homme en tant qu'outil de résistance et de transformation sociale des communautés autochtones et des organisations paysannes au Paraguay à travers une étude de cas. II s'agit d'une étude à perspective qualitative qui, en analysant les répertoires juridiques utilisés par les mouvements sociaux, paysans et indigènes, a également examiné les facteurs qui les incitent à utiliser le droit et les droits de I'homme comme outil de résistance, qui a finalement permis d'identifier les principaux obstacles et limites pour garantir les droits humains de ces communautés et organisations dans le pays. Parmi les principaux résultats figurent la possibilité de changement normatif et de réparation sociale, considérés comme des opportunités politiques possibles qui pourraient promouvoir et étendre les droits de la population indigène-paysanne dans le pays, à condition qu'il y ait un environnement politique et institutionnel favorable, et, en outre, il existe des structures de support capables de supporter ce type de processus.

Mot-clés: Mobilisation socio-juridique, mouvements sociaux, structure d'opportunités politiques et droits de l'homme. 
摘要: 总的来说, 本文描述了一项研究, 通过案例研究, 分析了使用法 律和人权作为巴拉圭土著社区和农民组织抵抗和社会转型的工具的 可行性. 这是一项定性的研究, 通过分析社会, 农民和土著运动所使 用的法律手段, 还研究了影响他们利用法律和人权作为抵抗工具的 因素, 最终使查明保障该国这些社区和组织人权的主要障碍和局限 成为可能. 在主要结果中, 有可能进行规范性改变和社会赔偿, 只要 存在有利的政治和体制环境, 就可以认为这是可能促进和扩大该国 土著农民权利的政治机会, 另外, 还有能够维持这种过程的支撑结构 关键字: 社会法律动员, 社会运动, 政治机会结构和人权

\section{Introducción}

Con respecto al escenario local-regional en que se desarrolla el estudio, este abarca dos cuestiones centrales, por un lado: a) la "flexibilidad estatal", consecuencia de políticas neoliberales y la implementación de proyectos neoextractivos producto del Consenso de Commodities, y por otro, la movilización social, Svampa (2012). En este contexto ubicamos el caso paraguayo, en vista que en los últimos 20 años el país experimentó un incremento de movilizaciones sociales, de los sectores involucrados a este estudio.

En general, podría decirse que, entre los principales factores de movilización social de sectores indígenas y campesinos de la sociedad paraguaya, el problema se relaciona con cuestiones como: la concentración de la tierra, la apropiación y destrucción de la biodiversidad, y la expulsión de comunidades de sus territorios ancestrales. Si bien es cierto que los conflictos territoriales del país tienen su origen en los procesos históricos y políticos, como la entrega de tierras durante la dictadura, esto no excluye la idea de que a partir del establecimiento de empresas agroextractivas como las trasnacionales del agronegocio sobre los territorios campesinos e indígenas además de privatizar y desplazar a comunidades enteras, éstas han propiciado el aumento de movilizaciones sociales, Valiente (2019) a consecuencia de un modelo económico-productivo que los ha 
privado de su principal medio de subsistencia, la tierra, Svampa (2012).

La muestra está compuesta por dos Comunidades indígenas que han sido expulsadas de sus territorios ancestrales, luego de que sus tierras hayan sido vendidas por el Estado paraguayo, Comunidad Yakey Axa (Caso uno, 2005) y la Comunidad Sawhoyamaxa (caso dos, 2007), mientras que el tercer caso (20072018) lo compone la Coordinadora de Organizaciones Sociales de Tava'i que dirigió una manifestación social para impedir el cierre y demolición del único hospital de la zona para la construcción de un complejo ganadero, el resultado fue la condena a dos años de prisión de uno de los dirigentes campesinos.

Sobre las limitaciones del estudio, se subraya la dificultad que existió para acceder a los abogados o representantes legales de los casos, y, el acceso a las comunidades pues se encuentran ubicadas lejos de la capital. Para los criterios de inclusión se tuvieron en cuenta a comunidades indígenas y organizaciones campesinas que hayan hecho uso de las acciones o estrategias jurídicas para la defensa de los derechos humanos a nivel nacional e internacional

En general, el tema estudiado nace del interés del autor en dar respuesta a si el uso de estrategias jurídicas de protección a los Derechos Humanos funge como herramienta viable para el accionar de las organizaciones campesinas e indígenas de Paraguay como parte del proceso de movilización social. Y para esto, el estudio se divide en tres capítulos que intenta explicar el contexto regional-local en que se desarrollan los tres casos seleccionados para el estudio.

En el capítulo primero, se realiza un abordaje sobre los antecedentes investigativos, presentando algunos ángulos de estudios y modalidades de MSL, el objetivo de este capítulo es exponer la diversidad de criterios y los enfoques utilizados para estudios relacionados a la MSL, Peláez (2015; 2018). Todo esto, teniendo en cuenta que, en las últimas décadas, la MSL por los derechos a través del litigio, y la judicialización de casos ha sido 
empleada como parte de las estrategias de actores colectivos a nivel local, nacional e internacional, Hincapié (2018).

En esta misma línea, el capítulo segundo presenta las categorías teóricas, las dimensiones y las ideas centrales que explican la diferencia entre organizaciones y movimientos sociales a partir de lo que Velázquez (2005) entiende como la tercera ola de democratización en América Latina resaltando las similitudes y diferencias entre uno y otros, muy de cerca a esta categoría se encuentran las Estructuras de Oportunidad Política (EOP), donde se describen las oportunidades o restricciones que pueda brindar un determinado sistema político, Peláez (2018). Siguiendo en el capítulo segundo, en un tercer momento se profundiza sobre la necesidad de agregar la categoría de desventajas políticas, que busca examinar cuestiones que inhiben las acciones colectivas, Velázquez (2005). Para pasar, a describir los elementos analíticos de la movilización social como los procesos enmarcadores, estos se tratan de los significados compartidos que impulsan a las personas a la acción colectiva de esfuerzos estratégicos conscientes realizados por grupos de personas en orden de forjar formas compartidas de considerar el mundo, Peláez (2018).

En este orden ideas se encuentran las Estructuras de Movilización, donde se abordan la parte organizativa de cualquier proceso de movilización social. Y, para finalizar el capítulo se definen los repertorios, estos hacen referencia al conjunto de medios del que dispone un grupo para plantear sus reclamos y así lograr que estos sean atendidos y resueltos Peláez (2018). Son, por lo tanto, las formas a través de las cuales actúa un movimiento social. Cada época tiene repertorios que le son característicos y que responden a las experiencias acumuladas, a particularidades del contexto y a los patrones culturales del grupo que los utiliza.

Continuando, con la presentación del estudio, en el capítulo tercero se expone de forma detallada el análisis de los casos, donde se someten a la unidad de análisis presentada como parte del aparatado metodológico Peláez (2018), y, finalmente 
se presentan las conclusiones del estudio, entre los que se encuentran: la posibilidad del cambio normativo (caso dos) y la reparación social asumidos (caso tres) como posibles oportunidades políticas que lograrían impulsar y expandir el alcance de los derechos, siempre y cuando exista un ambiente político e institucional que lo favorezca, y, además se cuente con las estructuras de soportes suficientemente capaces de sostener este tipo de procesos.

\section{Modalidades de la Movilización Socio-legal}

De acuerdo con la línea de Peláez, existen dos modalidades de MSL, la primera, corresponde a la demanda, asociada o traducida en una demanda por el reconocimiento de derechos no regulados o reconocidos, por una exigencia de cumplimiento cabal de derechos existentes, o porque desaparezca una situación de violación flagrante a los mismos (MSL-Estricta) Peláez (2015). La segunda, es aquella donde la demanda fundamental no esté necesariamente puesta en clave de derechos, pero donde la lucha por los derechos o las estrategias jurídicas constituyen un aspecto importante del proceso de movilización social (MSLUso Estratégico). Dentro de esta modalidad pudiera ocurrir que, en algunas etapas de la movilización, el derecho esté ausente, mientras que en otros casos este es un elemento medular para la acción.

Sin embargo, la investigadora Mariana Manzo (2018), plantea que la MSL parte de tres principales estrategias de acción e interpretación; a) la estrategia jurídica-política de resistencia, ante violaciones a derechos es un recurso de batalla en la arena jurídica, se utilizan acciones procesales, individuales o colectivas; b) estrategia jurídica-política de reconocimiento de derechos, se utilizan fuentes del ordenamiento jurídico para reivindicar aquellos derechos o valores que se encuentran desvalorizados, invisibilizados o marginados en las interpretaciones que realizan las autoridades jurídicas, buscando activar su reconocimiento; c) estrategia jurídica-política de ampliación de 
derechos, esta pretende ser transgresiva y disruptiva de los valores dominantes, ya que desafía el espacio de posibilidad y pone en tensión lo jurídicamente pensable y no pensable, dentro y fuera del campo jurídico. Se caracteriza por la articulación de las dos primeras estrategias sentando un cambio paradigmático de derecho de los movimientos sociales que acompañan el proceso.

Esta perspectiva, de carácter explícitamente política surge de la necesidad de dejar de ver al derecho como monopolio único del Estado o como la única fuente del derecho, Rubial (2015). Por lo que apunta a la necesidad de visibilizar los procesos de interacción entre movimientos sociales y la movilización socio-legal del derecho. Visto que tiene por objetivo desafiar y transgredir el espacio de lo jurídicamente posible, para así instalar otros escenarios interpretativos, pero igualmente válidos en el ámbito jurídico. Es importante recalcar que, la estrategia jurídica no siempre es la más conveniente para promover las luchas sociales porque esta podría no representar las necesidades e intereses en juego de las comunidades o por el tiempo que implican para obtener resultados acorto plazo, Rubial (2015).

En síntesis, cualquier estudio que se pretenda realizar en torno a la acción colectiva y la movilización del derecho, debe comenzar por la ubicación del proceso organizativo dentro del contexto general de la sociedad.

\section{Movilización Socio-Legal}

En lo que concierne a MSL, en términos generales podríamos decir que constituye una de las formas específicas que asumen tanto los actores sociales como los movimientos sociales para hacer valer determinadas demandas, siendo el derecho uno de los elementos principales en dicha movilización. Este, se halla presente en algún ámbito de la acción colectiva (procesos enmarcadores, oportunidades, ambiente, estructuras de movilización y repertorios). En este sentido, lo que tipifica un proceso de MSL, es que el uso del derecho esté involucrado como un eje fundamental de la movilización. 


\section{Proceso de Movilización Social}

\section{Antecedentes y contexto político de la movilización}

A continuación, se señalan de forma general, ideas centrales por periodos que ayudan a situarnos en el escenario político, económico y social en el que se desarrollaron los hechos de cada caso. El primer periodo (1811-1869) abarca la independencia del Paraguay (1811), desde entonces, los regímenes políticos que han gobernado el país saquearon y despojaron de sus hábitats tradicionales a comunidades indígenas y campesinas.

Para el segundo periodo $\left(1870^{2}\right)$, la situación indígena no había cambiado, este correspondería a la posguerra de la Triple Alianza contra el Paraguay. Durante esta fase el Estado se encontraba en una crisis económica, consecuencia de haber perdido la guerra y como salida a las deudas comenzó a vender las tierras fiscales, sin tener en cuenta a los habitantes de las mismas. El resultado fue la entrega de inmensos latifundios a empresarios ingleses, brasileños, estadounidenses, franceses y en menor medida a paraguayos ${ }^{3}$. Luego de concretar las ventas, las empresas comenzaron a operar en rubros como: la extracción de madera, yerba, ganado o simplemente la especulación inmobiliaria, y se produce el inicio de un tercer periodo (19601990), Ávila C. \& García L. (2019). Este lapso se caracterizó por

2 El punto de inflexión fue la Guerra de la Triple Alianza (1864-1870) en la que Argentina, Brasil y Uruguay apoyados por Gran Bretaña diezmaron la población de Paraguay y le arrebataron miles de kilómetros cuadrados de su territorio. Las salidas económicas buscaban saldar deudas que le fueron impuestas.

3 “Es importante, recordar que un primer intento del Estado Paraguayo de expansión del capitalismo al campo, se dio en la década del 60, momento en el que fue impulsado el "Plan del Trigo" por el gobierno dictatorial de Alfredo Stroessner. El mismo nació como medida política de la "Revolución Verde", que implicó el endeudamiento de Paraguay a partir de la recepción de los créditos de la Alianza para el Progreso impulsada por los EEUU. Se lo puede ubicar de manera predominante, a partir de la década del 70' con la entrada de la soja brasilera que, a su paso desplazó a la ganadería, deforestó bosques y expulsó poblaciones campesinas e indígenas de sus territorios. Este ingreso se dio a través de las fronteras de la Región Oriental con Brasil, particularmente en los departamentos de: Alto Paraná, Amambay, Canindeyú, Itapúa. 
el ingreso del capital brasileño, impulsado por la dictadura stronista, que va lentamente introduciendo los primeros cultivos de soja en la década del setenta.

En lo que respecta al último y cuarto periodo, desde 1990 a la actualidad, es el momento de consolidación de los agronegocios en el país, implica la intensificación del cultivo de grano para exportación, la mayor presencia de multinacionales, la aprobación de semillas transgénicas y la importación de más agrotóxicos y más potentes, (Irala A., kretschmer R., y Palau Marielle: 2019). Además, no debemos olvidar que entre los años 1989 a 1992 se produce la llamada transición democrática.

En síntesis, el contexto histórico y político en que inician los Casos Yakye Axa y Sawhoyamaxa, se remontan a dos momentos de la historia: primero, la venta de tierras públicas como salida a la crisis económica de la posguerra, momento en que se asientan las bases de un estructura económica latifundista y trasnacional dedicada a la explotación forestal y la ganadería extensiva, Ávila C. \& García L. (2019), segundo momento, el período dictatorial, donde el gobierno a través de una manifiesta corrupción otorgó más de once millones de hectáreas de tierras destinadas a la reforma agraria, a correligionarios, militares y amigos, constituyéndose en la segunda importante concentración de la tierra a través del latifundio, Mendieta (2015).

\section{Características del lugar, composición social}

La geografía de Paraguay se divide en dos regiones, separadas por un río que lleva su nombre (Paraguay). Por un lado, la región Oriental, al sur, en donde se encuentra la mayor densidad poblacional y la región Occidental, al norte, conocida como Chaco, Mendieta (2015). En el país existen 19 pueblos indígenas, integrados por cinco familias lingüísticas, conformando una población de alrededor de 117.000 indígenas que totalizan el 1,8\% del total del país.

Si nos referimos a los habitantes del Chaco paraguayo en la actualidad, podemos sintetizar una dicotomía entre un pequeño 
grupo de personas y empresas que tienen latifundios y estancias agropecuarias, y otro gran grupo de personas, principalmente indígenas, que viven en comunidades y que en gran medida, antes que vivir, sobreviven a un Estado que se encuentra presente cuando hablamos de garantizar los intereses particulares de los primeros, y ausente cuando se trata de garantizar los derechos humanos de los segundos. Dado que hasta el siglo XIX, el Chaco paraguayo era territorio indígena.

\section{Actores intervinientes los Proceso}

El establecimiento de los emprendimientos agroextractivos en la región han desatado conflictos sociales que por un lado involucran a actores como las empresas trasnacionales del agronegocio, especuladores inmobiliarios, ganaderos, y por otro, a las Comunidades Indígenas (Caso uno: Comunidad Indígena Yakye Axa, y, Caso dos: Comunidad Indígena Sawhoyamaxa) desplazadas de sus territorios ancestrales por el avance de este tipo de empresas. Por último, debemos señalar a un tercer actor, el Estado, que asume el papel de vocero y promotor de las empresas nacionales y trasnacionales.

\section{Tipo de MSL y Objetivos de la Movilización}

En lo que respecta al objetivo de la movilización de la Comunidad Yakye Axa y la Comunidad Sawhoyamxa, ambos desde el principio, apuntaba a la defensa y la activación del derecho colectivo sobre el territorio ancestral, la protección, y, efectivización de sus derechos, por lo que también se trata de un uso estricto de derecho que se enmarca en la defensa de derechos humanos, pues a nivel local y nacional las Comunidades no pretendían algo más que la protección y el reconocimiento sus derechos.

Sin embargo, cuando el marco de acción se traslada al escenario trasnacional, la lucha Sawhoyamaxa, que se enmarca en la defensa del territorio y los derechos humanos, hace un doble uso de ambos marcos; por un lado, como instrumento de 
denuncia pública, para visibilizar internacionalmente la discriminación y violaciones cometidas hacia la comunidad indígena del país, y, por otro, como una herramienta capaz de generar cambios normativos que cumplan con los estándares internacionales de los derechos humanos.

El proceso histórico del que hace parte la Comunidad Yakye Axa, ha sido ejemplo para otras comunidades indígenas que se encuentran en una situación semejante. De hecho, la reivindicación y la demanda por el territorio se han convertido en la raíz de la desigualdad social para la población indígena y no indígenas del país. Es más, si nos abocamos a los mayores conflictos políticos que se han dado en el Paraguay, posiblemente el $90 \%$ de ellos corresponde a la mala distribución de las tierras o la ilegalidad de las mismas. Sin embargo, las respuestas del Estado siempre han sido la vía de la represión y la sistemática violación de derechos humanos.

\section{Procesos enmarcadores}

Sobre este punto debemos tener en cuenta que, el proceso en el cual se enmarca la lucha y resistencia local de ambas Comunidades indígenas se ha ido modificando durante los más de veinte años que han durado ambos procesos de reivindicación territorial. Sobre todo, para la Comunidad Yakye Axa, en vista que al día de hoy (2020) no ha finalizado su proceso.

Por un lado, podríamos decir que, a nivel local, ambas movilizaciones se enmarcaron en la Comunalidad $y$ defensa del territorio indígena para lo cual hacen uso de los derechos humanos como repertorio de acción colectiva. En este marco, la comunidad está profundamente vinculada al territorio debido a la relación no sólo en lo físico, material, sino también en lo simbólico, sentimental hasta lo cosmogónico. Esta concepción del territorio, unido con la vida misma, constituyó la base que permitió contar con redes comunitarias informales densas como forma de movilización para el proceso, (Herrera E.; Leyva A., y Peláez, J. (2020)). 
Este tipo de marco surge de los movimientos de base indígena donde la comunidad se rige por la Asamblea Comunitaria y el Consejo de Ancianos como máxima autoridad comunitaria, donde la exigibilidad de derechos indígenas pasa de ser una cuestión de leyes a un tema de participación activa durante los procesos políticos, económicos y sociales, que afectan a los miembros de la comunidad. En general, los partidarios de este marco asumen una postura sobre la defensa del medio ambiente y la naturaleza, lo que está relacionado con el "giro ecoterritorial" donde los movimientos comienzan a configurarse en tipo socio-ambiental-territorial, Peláez (2018).

Dentro de este marco, la defensa de derechos humanos cumple la función de ideas aglutinantes, tanto para organizaciones y movilizaciones comunitarias, indígenas y campesinas, que utilizan y hacen uso de los mismos, Peláez (2018), como herramienta para exigir un manejo adecuado de las instituciones públicas encargadas de proteger y garantizar su cumplimiento, Svampa (2012).

\section{Movilización del Derecho y de los Derechos Humanos}

La movilización del derecho y de los derechos humanos no siempre fue parte de la movilización y la organización colectiva de la Comunidad Yakye Axa, y peor aún, de la Comunidad Sawhoyamaxa. Esta empieza a formar parte después de que el ambiente político e institucional fuera favorable para la población paraguaya en general, aquí debemos recordar que los 35 años de dictadura militar que vivió el país limitaron enormemente la capacidad organizativa de la sociedad. En este sentido, la Comunidad Sawhoyamaxa comienza el proceso de organización política y resistencia durante la transición democrática (1990), momento en el que decide utilizar el derecho como herramienta para hacer frente a las empresas ocupantes. Entre las estrategias utilizadas en este ámbito del proceso se encuentran las siguientes: demanda vía derecho administrativo; por el reconocimiento de derecho colectivo; medidas cautelares, 
amparo y acción inconstitucionalidad contra las Empresa arrendataria de las tierras; litigio a nivel internacional y una modificación en el reglamento interno; proyecto de Ley de expropiación de los inmuebles a favor de la Comunidad. En esta última, los esfuerzos durante las primeras etapas se concentraron en generar información suficiente, difundirla y tejer alianzas con otras organizaciones.

En lo que toca a las oportunidades políticas, se hizo uso del derecho, derechos de los pueblos indígenas y los derechos humanos como repertorios y procesos enmarcadores. Empecemos por ubicar el lugar que ocupó el derecho dentro del Caso Sawhoyamaxa, primero; y al igual que el caso uno, la movilización del derecho se dio una vez que el ambiente político e institucional fue favorable para la Comunidad.

Como se mencionó en otros apartados, la MSL del Caso Sawhoyamaxa es una MSL en sentido Estricto, porque tuvo como base el uso de repertorios jurídicos como centro de la acción colectiva. Este marco de movilización también se relaciona con marcos y niveles más amplios como: el marco de la defensa del medio ambiente, los Derechos Económicos, Sociales, Culturales y Ambientales (DESCA), la defensa del territorio, postura que consiste y apunta a una democratización real de las decisiones que afectan fuertemente las condiciones de vida de los sectores más vulnerables y comprometen el porvenir de las futuras generaciones. Podemos decir que, el proceso demostró que el uso del derecho como repertorio de movilización social resulta útil si va acompañado de otros repertorios y si los actores movilizados cuentan con fuerza política y estructuras de movilización versátiles y diversas.

\section{Tipo de Movilización Socio-legal}

Ahora bien, la estrategia de activar mecanismos internos para acceder al territorio no arrojó los resultados esperados, en vista a factores que modifican las EOP, como, la burocracia y corrupción. En consecuencia, ambas Comunidades acuden a 
instancias internacionales, donde la Corte Interamericana considera que el Estado ha violado los derechos humanos de las mismas y ordena una serie de medidas de reparación.

Sin embargo, a pesar de las sentencias dictadas a favor de ambas Comunidades, estas no tuvieron impactos directos ni inmediatos. Por ejemplo, el cumplimiento de sentencia en el caso Sawhoyamaxa se dio luego de nueve años de haberse emitido, el poco avance para efectivizar las medidas hizo que los miembros de la Comunidad Sawhoyamaxa decidan reocupar sus tierras aun sobre la negativa de empresarios y sin intervención del Estado (2013).

Durante el primer año de reocupación, sin mayores trabas al asunto, el Congreso Nacional, decide por fin aprobar la ley de expropiación a favor de la comunidad e incluso al poco tiempo de haberlo hecho, sucede algo sin precedentes, la Corte Suprema de Justicia decidió "no hacer lugar", a una acción de inconstitucionalidad ${ }^{4}$ promovida contra la referida Ley de expropiación favoreciendo a la Comunidad. En este punto, es importante señalar un factor que pudo haber influido para la expropiación de las tierras a favor de la Comunidad Sawhoyamaxa. El factor identificado, se relaciona con el ambiente político y la inestabilidad institucional de aquel periodo porque la reocupación de los Sawhoyamaxa fue a 11 meses de una de las mayores crisis política del país, la Masacre de Curuguaty, donde policías quisieron desalojar a campesinos que ocupaban tierras en esa localidad y terminó con un total de 17 muertos y la destitución del presidente paraguayo Fernando Lugo.

\footnotetext{
4 Se trata de una acción de inconstitucionalidad contra el artículo 3 de la Ley de expropiación, promovida por el representante legal de las empresas Kansol S.A. y Roswell Company S.A. Con anterioridad, las mismas empresas habían planteado una acción de inconstitucionalidad contra la referida ley de expropiación, en su integridad, que fue declarada sin lugar por la Corte Suprema del Paraguay en septiembre de 2014, lo cual fue constatado por la Corte Interamericana (supra Considerando 13). Cf. Acuerdo y Sentencia No. 384 emitida por la Corte Suprema de Justicia del Paraguay de 2 de junio de 2015 (Anexo al informe presentado por el Estado el 4 diciembre de 2015).
} 
No obstante, en el caso de la Comunidad Indígena Yakye Axa, tampoco se dio cumplimiento a la sentencia internacional de forma inmediata, incluso a pesar de las malas condiciones de vida de sus miembros. Las solicitudes de expropiación tramitadas por el INDI fueron rechazadas en tres ocasiones en el legislativo. Sobre esto, debemos mencionar que los resultados de investigaciones realizadas señalaron en su momento como verdadero propietario de las tierras a un ex financista de plaza, Oscar Carísimo Netto, ligado a la crisis bancaria paraguaya de mediados de los '90 provocada por el manejo de dinero en negro. Y, a finales del año 2001, las firmas arrendadas y administradas por la firma comercial de plaza Torokay S.A. Agropecuaria y Forestal transfieren las tierras a manos de Julio Osvaldo Domínguez Dibb ${ }^{5}$, empresario con mucho poder ligado a Carísimo Netto.

Es así que, luego de casi 10 años de no haber cumplido a cabalidad con las medidas ordenadas, y ante la denuncia de casos similares a los analizados aquí, el tribunal internacional durante el proceso de supervisión de sentencia, nuevamente reafirma la necesidad de un cambio normativo debido a que el procedimiento actual es inadecuado para la reivindicación de territorios ancestrales de derecho indígena.

Teniendo en cuenta que activar mecanismos internos $\mathrm{y}$ procedimientos jurídicos ha sido la estrategia central de ambos Casos y que estas no han generado los resultados esperados a corto plazo, podemos observar que el problema no es exclusivo de la falta de mecanismos y procedimientos internos, sino que la problemática también involucra cuestiones relacionadas a la operatividad de las instituciones al momento de proteger $\mathrm{y}$ garantizar los derechos humanos de la población afectada en

\footnotetext{
5 Osvaldo Domínguez Dibb: es miembro de una familia muy emparentada cercana al dictador Alfredo Stroessner. Dueño de la tabacalera Boquerón S.A. 2005. La empresa fue demandada por cuatro Estados norteamericanos, Oklahoma, Nebraska, Michigan y Missouri, acusada de falsificación de cigarrillos. Entre otras cosas el mismo fue presidente de club Olimpia, ex candidato a la presidencia colorada y, propietario de varios medios de información.
} 
estos casos, sobre todo cuando estos colisionan con los derechos de propiedad privada.

Acorde con lo anterior, la idea de un cambio normativo no estuvo contemplada de forma explícita por la Comunidad Sawhoyamaxa, pero, sin duda marca una línea de acción a seguir, siempre y cuando se cumpla con los criterios de progresividad de los derechos humanos y se logre abrir espacios institucionales de negociación que aún se encuentran clausurados.

\section{Alcances de la MSL-MS}

El objetivo de las Comunidades fue el reconocimiento de los derechos colectivos sobre su territorio, pero para esto necesitaban desarrollar estrategias y repertorios jurídicos-políticos capaces de generar los procesos organizativos locales y la movilización social, para lo cual se hace uso de un repertorio político, el cual utilizó las herramientas jurídicas que ofrece el discurso de derechos humanos para generar la articulación de diversos actores a nivel nacional.

Además, debe señalarse que la movilización tuvo efectos positivos y negativos importantes a largo plazo, por un lado, los niveles de movilización local, nacional y trasnacional, que arrojaron resultados en escalas diferentes, donde la más importante es el cambio normativo del Estatuto de Comunidades Indígenas, que deja un posible repertorio jurídico y más efectivo, para garantizar los derechos humanos de las Comunidades del país.

En general, los alcances de la MSL en cuanto al tipo de uso de los derechos humanos, son utilizados como instrumentos jurídicos que, en el mejor de los casos, son capaces de generar espacios y oportunidades que contribuyan, en alguna forma, para que las organizaciones comunitarias, movimientos y grupos en lucha cuenten con repertorios jurídicos y marcos que aporten a su lucha. 


\section{Estructuras de movilización}

Han sido varias las organizaciones y actores que participaron a lo largo de los veinticuatro años del proceso de movilización socio-legal que abarcan los Casos (uno y dos). Cada uno, con diferentes niveles de involucramiento y en distintos momentos, pero cumpliendo una importante labor. Sin embargo, lo que permitió al proceso de resistencia indígena mantenerse en pie durante estos años es la Comunidad y su relación con el territorio.

Por ejemplo, como parte de las estructuras organizativas antes, durante y después de la MSL, se identificaron tres componentes relacionados. El primero, consiste en las formas de organización, formales e informales, anteriores o sobrevivientes, a través de estas los miembros de la Comunidad han logrado involucrarse en la acción colectiva. Aquí se ubican a los actores locales: miembros del Caso Yakye Axa, el Consejo de Ancianos y a la Comunidad misma.

El segundo, vinculado a las redes conectivas consensuadas, estas permitieron a la Comunidad conectarse con diversos actores en distintas escalas y con responsabilidades varias. Aquí se citan a los movimientos y organizaciones locales que han acompañado el proceso a nivel local, nacional y trasnacional, entre los que se encuentran, los partidos políticos, defensores de derechos humanos, asociaciones internacionales, además, desde 1999, la Coordinadora de Derechos Humanos del Paraguay (CODEHUPY), la ONG Tierra Viva ${ }^{6}$, el Centro por la Justicia y el Derecho Internacional (CEJIL), las organizaciones internacionales de derechos humanos, investigadores, defensores de

6 En lo que respecta a la ONG Tierra Viva, que, desde 1994 se dedicó a trabajar en la promoción y defensa de los derechos humanos de los Pueblos Indígenas, con énfasis en la restitución territorial, siendo el derecho territorial el eje a partir del cual se ensamblan las diversas acciones y líneas de acción, entre estas se mencionan: el litigio estratégico, la incidencia en políticas públicas, la capacitación, el fortalecimiento organizacional, formación política y jurídica, así como el asesoramiento general, son sus principales trabajos orientados a la exigibilidad de derechos. http://www.tierraviva.org.py/ 
derechos humanos, actores que jugaron papales fundamentales. Las mismas, cumplen la función de articulación de los distintos esfuerzos.

\section{Caso Tres: La Coordinadora de Organizaciones Sociales de Tava'i}

En el caso de la Coordinadora de Tava'i (en adelante) también es uso Estricto del derecho, se trataba de la defensa y activación de derechos reconocidos constitucional e internacionalmente. Por un lado, durante la primera fase (2003-2008) la Coordinadora de Tava'i buscaba impedir el cierre del hospital y la venta del inmueble, a través del uso de repertorios como: la manifestación social permanente, las solicitudes al Estado para que no permita la privación de un derecho fundamental como el acceso a salud de la Comunidad.

Po otro, en la segunda fase, se da posterior a la detención del dirigente campesino, quien fue condenado a prisión domiciliaria con la prohibición de participar en reuniones de más de tres personas durante dos años. En este punto, también es importante resaltar que la Coordinadora de Tava'i emergió en el 2007 con un claro objetivo, impedir cierre del hospital, sin embargo, luego de que uno de los dirigentes haya sido condenado a prisión domiciliaria, y, el ahora dueño ${ }^{7}$ del predio en disputa lo convirtiera en un complejo ganadero, la Coordinadora deja de operar en el año 2012, lo confirma la tan efectiva estrategia de desmovilización del Estado.

Durante la tercera fase, tras haber agotado la instancia interna, la defensa de Evelio presenta ante el Comité de Derechos Humanos de las Naciones Unidas una denuncia contra el Estado paraguayo por haber violado el derecho de Giménez igualdad ante la ley (Declaración Americana sobre Derechos Humanos, Capítulo II. Art. $\mathrm{n}^{\circ}$. 4.,1969) la presunción de

7 En parte de la entrevista al dirigente campesino, este refirió que el ex asesor jurídico de la fundación es el actual dueño del complejo ganadero. 
inocencia (Art. 15); y de reunión pacífica (Art.21) de Evelio Ramón Giménez, derechos reconocidos en el Pacto International de Derechos Civiles y Políticos (PIDCP).

En general, podríamos decir que, durante la fase una y dos no existió MSL propiamente dicha, pues la defensa se dedicó a la defensa del dirigente detenido, pero, a partir de la tercera fase o movilización trasnacional, la lucha por los derechos de la Comunidad vuelve a ser el centro de la movilización, pero esta vez, la defensa de los derechos se da a partir del uso de repertorios jurídicos. Si bien, la ausencia de este en la fase uno se debió tanto al contexto en que se produjo la movilización como a la falta de profesionales del derecho que pudiesen brindar asesoramiento al momento de la movilización campesina del distrito de Tava'i.

En este marco, la estrategia jurídica se trata del litigio Internacional con el objetivo de abrir espacios políticos e institucionales de negociación con el Estado, clausurados por la criminalización de medios de expresión y protesta política de los sectores campesinos, Valiente (2014). En respuesta, el Comité señaló que la defensa de Evelio no fundamentó suficientemente la queja sobre la arbitrariedad y denegación de justicia por lo que no fue admitida (Dictamen C.D.H. núm. 2372/20,2018). No obstante, sobre el punto de restricción del derecho de reunión pacifica, señaló que el Estado estableció restricciones desproporcionadas sin ninguna base legal y que tampoco explica cómo en la práctica la participación de Evelio en una reunión de tres personas o más podía vulnerar los derechos y libertades de los demás o plantear una amenaza para la protección de seguridad y el orden público.

De este modo, el Comité indicó que el Estado paraguayo limitó indebidamente el derecho de libertad de reunión (Art.21) establecido en el PIDCP, violando el derecho de Evelio. Así mismo, el Estado está obligado a proporcionar una reparación efectiva, lo que incluye el reembolso de las costas procesales y una indemnización además de tomar medidas para evitar que se cometan violaciones semejantes en el futuro. 
Si bien, la denuncia no fue admitida en su totalidad, pero podríamos decir que la estrategia jurídica ha cumplido medianamente con su propósito de generar espacios de participación política dentro de las instituciones públicas. En este sentido, es que la propuesta presentada por las organizaciones y el dirigente a punta a una "reparación social" y colectiva para la Comunidad de Tavea i. Estas consisten en la construcción de un hospital con la provisión o dotación de equipamiento adecuado, y la modificación del código procesal penal de forma a que no se repita el atropello de prohibir asistir a reuniones a cualquier otra persona vinculada a las reivindicaciones sociales.

Acorde con esto, la Comisión Interinstitucional para el Cumplimiento de Sentencias Internacionales (CICSI), se reunió con el dirigente campesino abogados de la CODEHUPY y Base IS. Los representantes mostraron interés y predisposición para llegar a un acuerdo de reparación con el fin de resarcir los derechos que fueron violentados contra Ramón Giménez.

Durante una entrevista realizada a Evelio en el marco de este estudio, él mismo refirió que la propuesta presentada a la CICSI abarca dos cuestiones centrales para cumplir el acceso a la salud de miembros de la Comunidad de Tavea $i$, el primero consiste en la construcción de un hospital, dotación de equipamiento adecuado, ambulancias, una farmacia de carácter comunitario y el nombramiento de funcionarios y funcionarias médicas profesionales que hacen falta en la Comunidad. Y, el segundo punto, la posibilidad de que el caso de Evelio Giménez sea conocido en la Escuela Judicial y en el Centro de Entrenamiento del Ministerio Público para que los futuros fiscales y jueces internalicen la prohibición de restringir un derecho constitucional en el marco de un procedimiento penal. Por el momento la propuesta se encuentra siendo analizada por la CICSI.

\section{Conclusiones finales}

A continuación, se exponen los principales resultados de la investigación: 
PRIMERA. Sobre los factores de viabilidad del uso del derecho y los derechos humanos como herramienta de resistencia y transformación social por parte de comunidades indígenas y organizaciones campesinas en los tres casos por igual, los resultados indican que existe la posibilidad o viabilidad para este tipo de usos, siempre y cuando los repertorios jurídicos sean articulados a otros repertorios propios de la acción colectiva, y además, cuenten con estructuras sólidas de movilización ya que sin estos elementos sería imposible sostener los procesos MSL.

SEGUNDA. Los factores que inciden para que las comunidades indígenas y organizaciones campesinas hagan uso del derecho y los derechos humanos como herramienta de resistencia, han sido: la privación del territorio a estas comunidades, situación que ha convertido el uso de repertorios jurídicos y la acción colectiva en herramientas útiles para disputar al Estado la falta de garantías y de protección necesaria sobre los derechos humanos de estas comunidades a nivel nacional. Sin embargo, no podemos olvidar otros factores de incidencia como: el ambiente político, y sobre todo las consecuencias negativas del modelo productivo del país.

TERCERA. Los elementos identificados como obstáculos o límites para garantizar los derechos humanos de comunidades indígenas y organizaciones campesinas en Paraguay, entre los principales se señala al modelo productivo, factor desencadénate del proceso de desterritorialización de las comunidades en cuestión; el enclaustramiento político de un sector en el poder que influye e incide sobre la implementación de políticas impositivas al sector agroempresarial para el financiamiento de políticas públicas; la falta de garantías institucionales para dar cumplimiento a las sentencias en los últimos 15 años; la criminalización de la lucha social, para desmovilizar a las comunidades indígenas y organizaciones campesinas; y además, la falta de mecanismos internos que protejan los derechos de pueblos, comunidades indígenas y campesinas del país.

CUARTA. Dos resultados claves: el primero, a nivel localnacional aún quedan pendientes la posibilidad del cambio 
normativo sobre el Estatuto de Comunidades Indígenas y la reparación social propuesta en el Caso de Evelio porque son procesos inacabados.

No obstante, estos resultados, son asumidos como una ventana de oportunidad que podrían impulsar y expandir los derechos de la población indígena-campesina en el país, siempre y cuando exista un ambiente político e institucional favorable y se cuente con las estructuras de soportes suficientes para sostener el proceso. Segundo, relacionado a la centralización de las ONG's que actúan como estructura de soporte en los casos, si bien, es cierto que el apoyo proporcionado ha sido fundamental, pero la ubicación geográfica (rural-urbana) de estas, sin duda habría influido bastante para que las tres Comunidades (Yakye Axa, Sawhoyamaxa, y la Coordinadora de Tava'i ) puedan acceder a ellas y solicitar ayuda o colaboración, por ejemplo; en tercer caso, el proceso ante el Comité de DD.HH. llega al nivel internacional únicamente porque las organizaciones se acercan a la familia, como lo expone el dirigente durante la entrevista realizada.

\section{Bibliografía}

Ávila, Claudia \& García, Lis (2019) "Atlas del Agronegocio en Paraguay" en BASE Investigaciones Sociales. Fundación Rosa Luxemburgo. Asunción, Paraguay. En línea en: http://www.baseis. org.py/wp-content/uploads/2020/03/2019_Dic-ATLAS.pdf.

Corte Interamericana de Derechos Humanos (2005). "Comunidad Indígena Yakye Axa vs. Paraguay”. Sentencia. En línea en: http:// www.corteidh.or.cr/docs/casos/articulos/seriec_125_esp.pdf.

Corte Interamericana de Derechos Humanos (2019). "Comunidades Indígenas Yakye Axa, Sawhoyamaxa y Xákmok Kásek Vs. Paraguay". Supervisión de Cumplimiento de Sentencia. En línea en: http://www.corteidh.or.cr/docs/supervisiones/yakye_axa_ 14_05_19.pdf.

Corte Interamericana de Derechos Humanos (2007). "Comunidad Indígena Sawhoyamaxa Vs. Paraguay". Fondo Reparaciones y Costas. Sentencia. Recuperado de: http://www.corteidh.or.cr/ docs/supervisiones/sawhoyamaxa_02_02_07.pdf. 
Herrera, Edith, Leyva, Alejandra, \& Peláez, Jorge (2020). "La lucha social contra proyectos mineros en la montaña de Guerrero, México: el derecho y los derechos como repertorio de movilización en defensa del territorio" en Globalización, neoliberalismo y derechos de los pueblos indígenas en México. UNAM. México. En línea en: http://ru.juridicas.unam.mx/xmlui/ handle/123456789/58503.

Hincapié, Sandra (2018). "Movilización sociolegal transnacional. Extractivismo y Derechos Humanos en América Latina” en América Latina Hoy. Revista de ciencias sociales. $\mathrm{N}^{\circ} 80$. Universidad de Salamanca. España. En línea en: https://gredos. usal.es/bitstream/handle/10366/142366/Movilizacion_sociolegal_transnacional_Ex.pdf?sequence=1\&isAllowed=y

Irala, Abel, Kretschmer, Regina, \& Palau, Marielle, (2019) Ocupaciones de tierra: marcas del conflicto rural (1990-2019). Editorial BASE Investigaciones Sociales. Asunción. En línea en: http:// www.baseis.org.py/wp-content/uploads/2020/03/2019_DicOcupaciones-de-tierras.pdf

Manzo, Mariana Anahí (2018) "La Movilización Del Derecho Por Movimientos Sociales: Dinámicas De La Política Radical De Transformación Y El Espacio De Lo Jurídicamente Pensable” en Revista Oñati Socio-Legal Series. N ${ }^{\circ}$ 5. Guipúzcoa, España. En línea en: http://ssrn.com/abstract=3278758

McAdam, Doug (1999). "Orígenes terminológicos, problemas actuales y futuras líneas de investigación” en Movimientos sociales, perspectivas comparadas: oportunidades políticas, estructuras de movilización y marcos interpretativos culturales. Editorial Istmo. Madrid

Peláez Padilla, Jorge (2015) "Derechos humanos movilización social: un marco analítico para su estudio", en Derechos humanos y trasformación política en contextos de violencia. UNAM, México. En línea en: https://sjlatinoamerica.files.wordpress. com/2016/05/pelaez-derechos-humanos.pdf.

Peláez Padilla, Jorge (2018). "La identidad precipitada. Los límites del derecho como marco para la acción colectiva" en Revista Oñati Socio-Legal Series. N ${ }^{\circ}$ 5. Guipúzcoa, España. En línea en: http://ssrn.com/abstract=3132406. 
Svampa, Maristella (2012) "Consenso de los commodities, giro ecoterritorial y pensamiento crítico en América Latina” en OSAL. $\mathrm{N}^{\circ}$ 32. Año 13. CLACSO. Argentina. En línea en: http://www. maristellasvampa.net/archivos/ensayo59.pdf.

Valiente, Hugo (2014) Comunidades en lucha: Cuatro demandas al Estado paraguayo por violación de Derechos Humanos. Editorial BASE Investigaciones Sociales. Asunción. En línea en: http:// biblioteca.clacso.edu.ar/Paraguay/base-is/20170331040456/ pdf_1210.pdf 